\title{
Information Mining for Urban Building Energy Models (UBEMs) from Two Data Sources: OpenStreetMap and Baidu Map
}

\author{
Chao Wang ${ }^{1,2}$, Yanxia $\mathrm{Li}^{1,2}$, Xing $\mathrm{Shi}^{1,2, *}$ \\ 1School of Architecture, Southeast University, Nanjing, China. \\ ${ }^{2}$ Key Laboratory of Urban and Architectural Heritage Conservation, Ministry of Education, \\ Nanjing, China.
}

*Corresponding author e-mail: shixing_seu@163.com

\begin{abstract}
Urban Building Energy Models (UBEM) are essential for urban energy related applications. The lack of publicly available data is widely acknowledged as one of the main barriers in the development of UBEM. Hence, open datasets such as OpenStreetMap (OSM) and Baidu Map (BDM) offer a significant potential to improve the quality and efficiency of data collection, integration, and processing in UBEM. This paper proposes methods to obtain three fundamental components, the information of building footprints, types and height, in a complete input dataset for UBEM, using OSM data and BDM data. The assessments of building footprints suggest that BDM data is superior to OSM data in completeness and shape accuracy. The accuracy of the determination of building types in OSM by taking advantages of the Tags or Values and the land use type is higher than that in BDM linked with Points of Interests (POIs). The information of building height is inadequate both in OSM and BDM. However, the transfer of altitude information from POIs to buildings could be realized in BDM, showing better quality in residential buildings than in office buildings. This study demonstrates that, despite of some defects, OSM and BDM still have great potential to be useful data sources for UBEM.
\end{abstract}

\section{Introduction}

In response to current energy shortage and environmental deterioration, many countries are developing long-term targets for energy conservation and greenhouse gas (GHG) emission reduction. The U.S. government has set the goal to reduce GHG emission in the range of $17 \%$ by 2020 and $26-28 \%$ by 2025 , compared with 2005 emission levels (Damassa et al., 2014). The European Union (EU) proposes that by 2020,2030 and 2050, the mission will have reduced GHG emission by $20 \%, 40 \%, 80-95 \%$, respectively, from 1990 levels (EU Climate Action, 2017). China's State Council also sets the target to reduce carbon dioxide emission per unit of GDP by $40-45 \%$ by 2020 , compared with 2005 (Approval of National Climate Change Response Planning, 2014). In order to meet these objectives, city officials are in urgent need for proper planning tools for an in-depth understanding of current urban energy demand, which is essential to the reduction of unnecessary energy consumption and GHG emission.

Urban Building Energy Model (UBEM), a bottom-up modelling technique distinct from traditional top-down modelling ones, has been widely accepted as a more appropriate method to support the implementation of energy efficiency strategies in urban policy (Cerezo Davila et al., 2017). The generation of an UBEM relies on the definition of numerous data inputs, including climate data, geometric data and non-geometric data (Reinhart and Cerezo Davila, 2016). In addition, a more detailed classification of the data inputs which contains geometric data, semantic data, occupancy-related data and meteorological data has been made and the inputs with the greatest impacts on the heating demand are identified (Nouvel et al., 2017). In fact, it is generally believed that the accuracy of the UBEM methods are positively related to the number and accuracy of the data inputs. However, the data collection is difficult and time-consuming. Moreover, the source of data is not clearly explained in many papers, hindering the transplantation of the research methods and thus limiting the development of UBEMs. Therefore, there is a high possibility of improving the data collection in order to reduce the gap between the available urban data and the specific data required for UBEMs (Monteiro et al., 2018). The Urban Building Database (UBD) such as CityBES (City Building Energy Saver) (Chen et al., 2017) and TEASER (Tool for Energy Analysis and Simulation for Efficient Retrofit) (Remmen et al., 2018) has been developed to support an information system for urban building energy simulation.

However, only if UBD has been established in the target city could researchers conduct studies on the analysis of energy consumption at urban scale. Although some researchers cooperate with governments to use cadastral survey data to create 3D (three-dimensional) city models, the privacy of data source imposes restrictions on the widespread use of the method. In addition, the obsolescence of some cadastral survey data might result in the inaccuracy of the UBEM. Thus, the data source which can be easily and quickly obtained, with high accuracy and high frequency of data updating is urgently needed for UBEM.

The data generated in cities has exponentially increased in the past years, benefiting from the open data source. Unlike closed data source, open source contributes to the investigation of the quality and accuracy of the data. Moreover, the available data from open data source promotes effective replication of the UBEM structure. Thus, the application of open data source will bring advantages to the better development of UBEM. 
This contribution aims at making a detailed discussion on the acquisition and evaluation of three crucial kinds of information mined from two open and free data sources: OpenStreetMap (OSM) and Baidu Map (BDM). Central district of Nanjing, China, an economic center of high energy consumption is chosen as the research area of this paper. Moreover, the models and the data of this research are integrated in Geographical Information System (GIS).

\section{Flow of UBEM methods}

UBEMs require a large number of data inputs, including climate data, geometric data and non-geometric data. Reinhart (2016) explains that geometric data consists of building footprints, building height and window opening ratios, and non-geometric data includes construction assemblies, occupant density, usage schedules, internal loads and system COP (Coefficient of Performance).

With the information of building footprints and building height, the buildings like the cuboid (LoD1, Levels of Details 1) could be built to form simple 3D city models. In addition, Nouvel (2017) puts that LoD1 is reliable enough to estimate the total heating demand of a district. Thus, it is vital to obtain the data of building footprints and height as accurately as possible.

Building types are also significant for UBEM, as the method of archetype buildings, one of the most popular methods for urban building energy simulation, is mainly defined by this data (Mata et al., 2014; Lin et al., 2017; Li et al., 2018).

Furthermore, the implementation of UBEM methods relies on a combination of tools. The GIS shapefiles (In SHP format) which contain the information of building footprints and building height could be automatically converted into 3D models using a custom component created in Grasshopper, a plugin to the CAD environment Rhinoceros 3D (Sokol et al., 2017). In addition, other attributive information, such as building type, could also be stored in the GIS shapefile. Figure 1 illustrates the flow of UBEM methods.

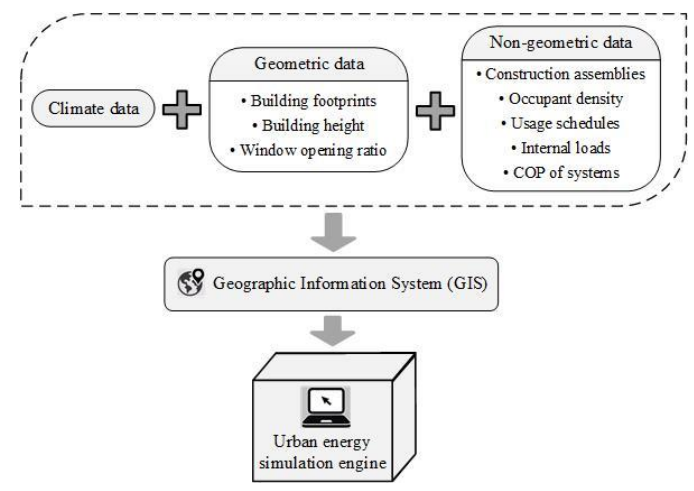

Figure 1: The flow of UBEM methods.

\section{Application of OpenStreetMap}

Thanks to the development of Web 2.0, Volunteer Geographic Information (VGI), which is a two-way cooperation between users and information providers, has emerged. With the efforts of a global cast of volunteers, the OSM is considered as one of the most successful VGI projects.
OSM has advantages of high shape accuracy and high frequency of data updating (Fan et al., 2014). The OSM data of this paper was downloaded from its official website (http://www.openstreetmap.org) on 27 November, 2018. These data in OSM format need to be transformed into GDB format, that could be used in the ArcMap (transformed in: https://geoconverter.hsr.ch/).

\section{Obtaining building footprints}

In China, four data types are available in OSM and used to represent objects, which are called points, lines, multilinestrings and multipolygons. Points refer to bus and train stations. Lines and multilinestrings represent highway and bus routes, respectively. Multipolygons denote buildings and lands.

The tags in multipolygons could be used to distinguish the buildings from lands. Based on five tags which are building, amenity, tourism, office and shop, 1,133 building footprints were obtained (Figure 2). These building footprints in GDB format could be transformed into shapefiles in ArcMap, prepared for UBEM.

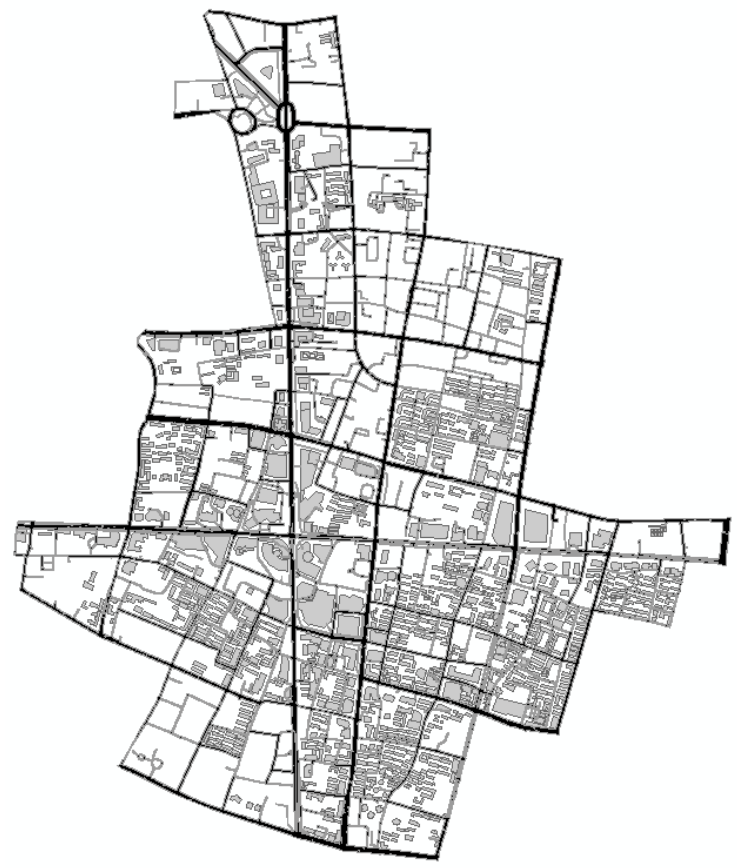

Figure 2: Building footprints extracted from OSM.

\section{Determination of building types}

According to Nouvel (2017), building types are strictly necessary, as wrong data would result in an error of over $30 \%$ on annual heating demand. Therefore, it is essential to use OSM data to make classification of building types. In this research, buildings are classified into 8 types: residential, commercial, office, medical, hotel, educational, commemorative and viewing. As mentioned above, the building footprints were extracted based on tags: building, amenity, tourism, office and shop. The tags of office and shop represent office buildings and commercial buildings, respectively. However, the tags of building, amenity and tourism may refer to various kinds of buildings, according to different values in these tags. The results of initial determination of building types are shown in Table 1. 
Table 1: Initial determination of building types.

\begin{tabular}{|c|c|c|}
\hline Building Type & Values (Tags) & Amounts \\
\hline Residential & $\begin{array}{c}\text { Apartments (b), } \\
\text { residential (b) }\end{array}$ & 30 \\
\hline Commercial & $\begin{array}{c}\text { Shop, commercial (b), } \\
\text { restaurants (b) }\end{array}$ & 36 \\
\hline Office & $\begin{array}{c}\text { Office, civic (b), office (b), } \\
\text { bank (a), post-office (a) }\end{array}$ & 56 \\
\hline Medical & Hospital (b), hospital (a) & 11 \\
\hline Hotel & Hotel (b), hotel (t) & 7 \\
\hline Educational & School (b), university (b) & 25 \\
\hline Commemorative & Place_of_worship (a) & 3 \\
\hline Viewing & $\begin{array}{c}\text { Arts_centre (a), library (a), } \\
\text { museum (t) }\end{array}$ & 3 \\
\hline Unknown & & 962 \\
\hline
\end{tabular}

Tags: (a): amenity, (b): building, (t): tourism

Through the method based on tags and values, only 171 building types could be defined, while the other 962 are still unknown.

The information of land use is very helpful, as it could complement the missing building information. For example, the buildings located on the residential lands are very likely to be residential buildings. Therefore, it is well-founded to obtain building types by the information of land use. Similar to the extraction of building footprints, 104 polygons of lands were obtained based on the tags of amenity, historic, landuse and tourism. However, as the land with the tag of landuse might contain more than one use, lowest priority should be given to the classification based on the tag of landuse so not to affect the accuracy of methods. For example, if a huge residential land (tag: landuse, value: residential) contains a small commercial land (tag: amenity, value: supermarket), the buildings on the smaller land should be considered as commercial buildings, rather than residential ones. In this way, the changes in the number of building types and the results of final determination of building types are shown in Table 2 and Table 3 , respectively.

Table 2: Changes in the quantity of building types.

\begin{tabular}{|c|c|c|}
\hline Building type & Values (Tags) & $\begin{array}{c}\text { Amounts } \\
\text { (added) }\end{array}$ \\
\hline Office & Courthouse (a) & +1 \\
\hline Educational & School (a), university (a) & +39 \\
\hline Residential & Residential (l) & +290 \\
\hline Commercial & Commercial (l) & +117 \\
\hline Unknown & & -447 \\
\hline
\end{tabular}

Tags: (a): amenity, (1): landuse

Table 3: Final determination of building types.

\begin{tabular}{|c|c|c|}
\hline Building Type & Amounts & Proportion \\
\hline Residential & 320 & $28.2436 \%$ \\
\hline Commercial & 153 & $13.5040 \%$ \\
\hline Office & 57 & $5.0309 \%$ \\
\hline Medical & 11 & $0.9709 \%$ \\
\hline Hotel & 7 & $0.6178 \%$ \\
\hline Educational & 64 & $5.6487 \%$ \\
\hline Commemorative & 3 & $0.2648 \%$ \\
\hline Viewing & 3 & $0.2648 \%$ \\
\hline Unknown & 515 & $45.4545 \%$ \\
\hline
\end{tabular}

The final diagram of building classification by OSM data is shown in Figure 3. About $55 \%$ of the total building types can be defined with the methods above.

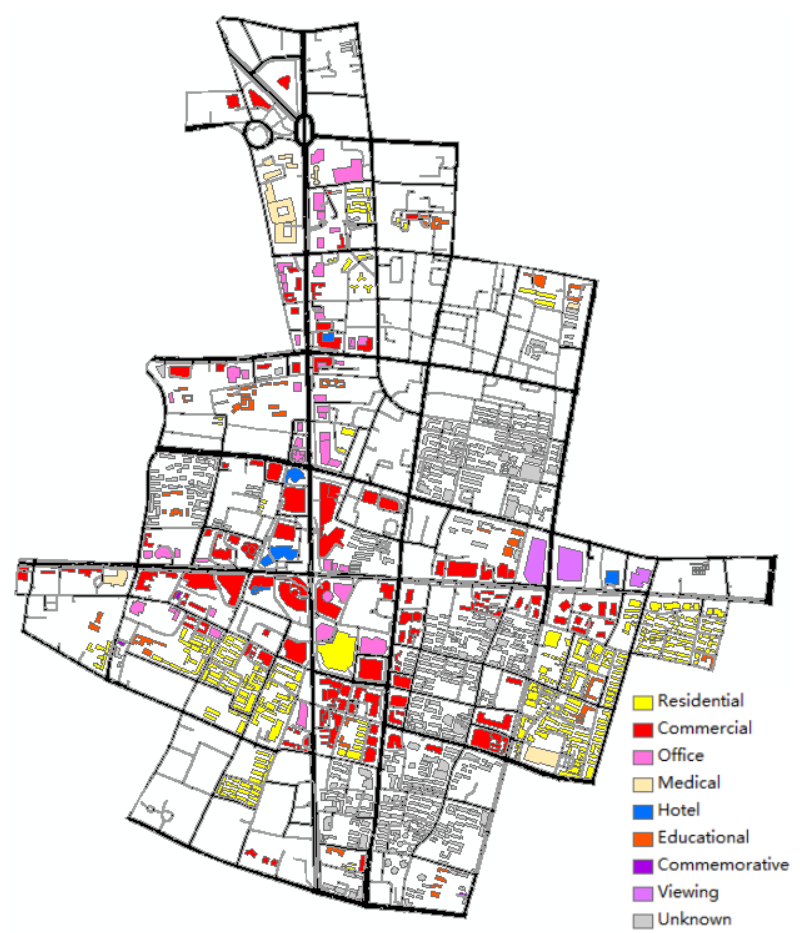

Figure 3: Building classification by OSM data.

\section{Obtaining building height or numbers of stories}

Unlike the OSM data in Germany (Alhamwi et al., 2017), there are no tags of height or building levels in OSM data of Nanjing. The information of building height or the numbers of stories could only be extracted from the tag of other_tags in multipolygons.

\section{Application of Baidu Map}

Baidu, one of the most successful Internet companies in China, announced that APIs (Application Programming Interface) of BDM were open to the public for free in April, 2010. The APIs have advantages of relatively cheap processing of massive map data, abundant data interfaces and high degree of user customization. The BDM itself has the information of building footprints. To extract this information, the users could apply for one key of the API (http://lbsyun.baidu.com/), and program to call the data. In this sense, BDM functions as a semi-open data source which relies on certain technologies to acquire data.

\section{Obtaining building footprints}

In this paper, the software BDMapCaptureVector $1.0^{\star}$, developed by Dr.Liu (Harbin Institute of Technology), was employed to obtain the data of building footprints on 23 November, 2018. This software is essentially a code package using the APIs of BDM. The data extracted from BDM in PNG format, needs to be vectorized in ArcMap, in order to acquire the data in SHP format. As Figure 4 shows, the map which contains 2,238 building footprints with no other information has been built. 


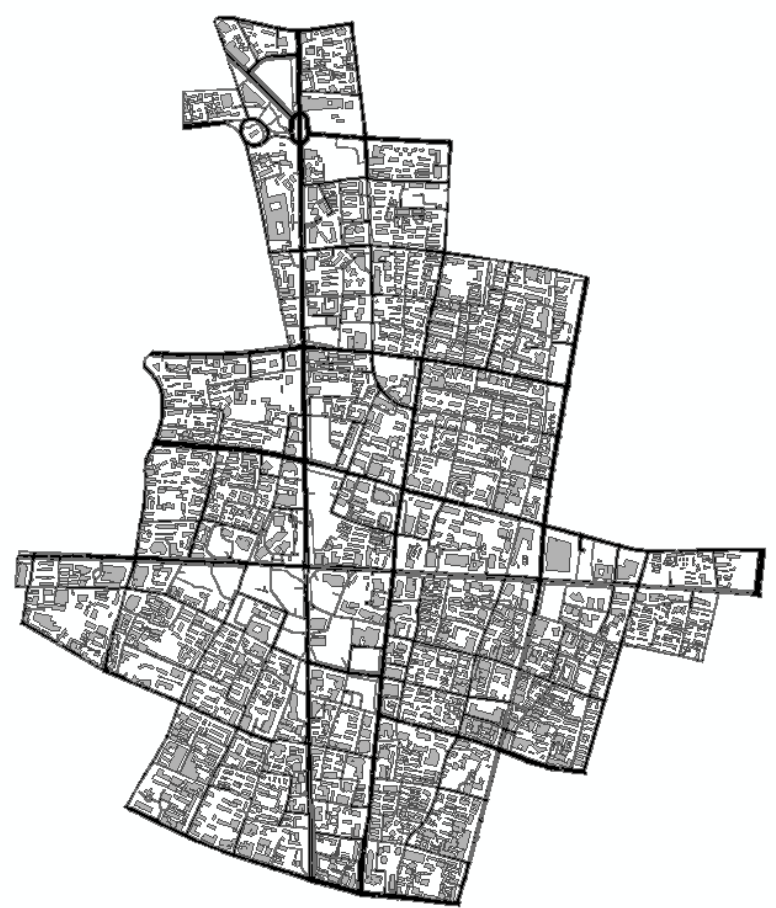

Figure 4: Building footprints obtained from BDM.

\section{Determination of building types}

In BDM, the determination of building types relies on POIs. POIs, the abbreviation of Points of Interest, represent those geographical entities that can be abstracted into points. POIs usually contain some useful attributive information which can be applied to the classification of urban buildings. In addition, the POIs from different sources may contain different kinds of information. This paper only introduces two kinds of sources, of which one is the commercial housing website in China, the other is the BDM itself. Both of them were analyzed and crawled by using python.

Table 4: Source of POIs and information contained.

\begin{tabular}{|c|c|}
\hline Source of POIs & Attributive information contained \\
\hline $\begin{array}{c}\text { Commercial } \\
\text { housing websites }\end{array}$ & $\begin{array}{c}\text { Name, longitude, latitude, numbers } \\
\text { of stories, construction year, etc }\end{array}$ \\
\hline Baidu Map & Name, longitude, latitude \\
\hline
\end{tabular}

It is clear in Table 4 that POIs from BDM only have three kinds of attributive information, compared with the rich information from some commercial housing websites. Theoretically speaking, all displayed information on the housing websites could be acquired so that the POIs with richer information could be obtained.

In order to determine which building footprint belongs to residential building, 277 POIs which contain information of building names, numbers of stories, longitude and latitude have been obtained from some commercial housing websites (housing rental). In addition, 113 polygon data of residential district were acquired from BDM by using APIs. The combination of building footprints, POIs and polygon data is shown in Figure 5.

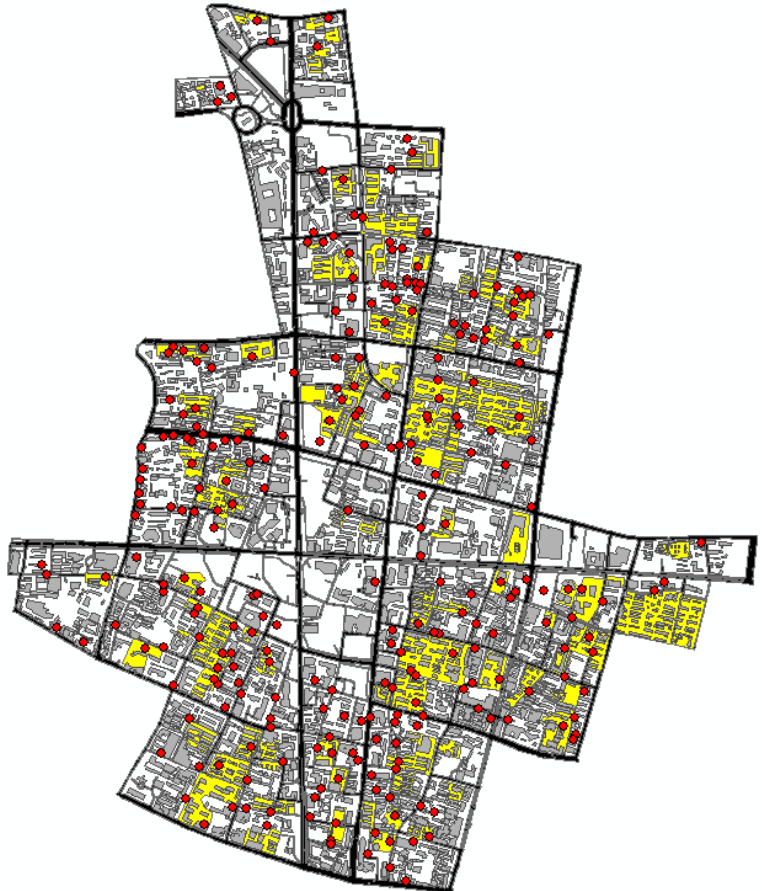

Figure 5: Combination of building footprints, POIs and polygon data.

As the polygon data represents residential districts, the buildings on these 113 polygons may be considered as residential buildings. With this method, 855 residential buildings have been defined. In addition, POIs obtained from commercial housing websites also can be utilized to determine residential buildings. It is found that 53 POIs are on building footprints rather than on the polygons of residential districts, which define 52 residential buildings. In addition, POIs of office buildings were also acquired from some commercial housing websites (office rental), including the same information as that of residential buildings. Except for these two building types, POIs of other types were all crawled from BDM, by using key words. For example, POIs of medical buildings were obtained by using the key word of hospital. The determination of building types is summarized in Table 5 .

Table 5: Determination of building types by POIs.

\begin{tabular}{|c|c|c|}
\hline Building Type & Source of POIs & Key words \\
\hline Office & $\begin{array}{c}\text { Commercial } \\
\text { housing websites }\end{array}$ & $/$ \\
\hline Commercial & Baidu Map & $\begin{array}{c}\text { shopping mall, } \\
\text { market }\end{array}$ \\
\hline Medical & Baidu Map & hospital \\
\hline Hotel & Baidu Map & hotel \\
\hline Educational & Baidu Map & school, university \\
\hline Commemorative & Baidu Map & memorial hall \\
\hline Viewing & Baidu Map & $\begin{array}{c}\text { museum, opera } \\
\text { house }\end{array}$ \\
\hline
\end{tabular}

Then, the combination of building footprints and POIs was conducted, in order to add the information of building types into building footprints. There are two steps in the combination, as shown in Figure 6:

(1) Combine building footprints with those POIs which 
are on the buildings.

(2) Set buffers with a radius of 5 meters for those POIs which are not on the buildings, and combine them with building footprints.

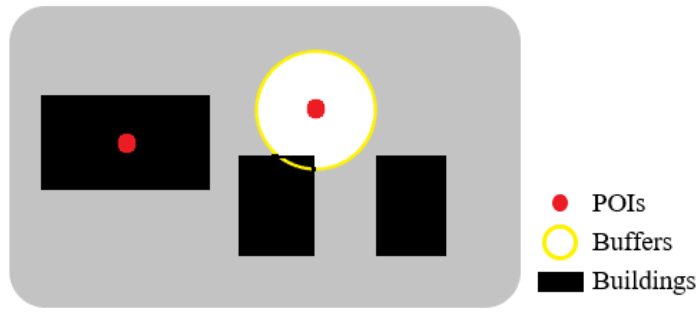

Figure 6: Technical route of combination.

The numbers of different kinds of buildings combined with POIs or buffers in each step are shown in Table 6, together with the final proportion of each building type.

Table 6: Amounts of defined building types.

\begin{tabular}{|c|c|c|c|c|}
\hline Building Type & Step1 & Step2 & Total & Proportion \\
\hline Office & 35 & 4 & 39 & $1.7426 \%$ \\
\hline Commercial & 4 & 1 & 5 & $0.2234 \%$ \\
\hline Medical & 15 & 6 & 21 & $0.9383 \%$ \\
\hline Hotel & 73 & 33 & 106 & $4.7364 \%$ \\
\hline Educational & 12 & 12 & 24 & $1.0724 \%$ \\
\hline Commemorative & 9 & 2 & 11 & $0.4915 \%$ \\
\hline Viewing & 5 & 0 & 5 & $0.2234 \%$ \\
\hline
\end{tabular}

Thus, with 907 residential buildings which have already been determined, 1,118 building types (about $50 \%$ of total buildings) can be defined with the above methods. The diagram of building classification by the combination of BDM and POIs is shown in Figure 7.

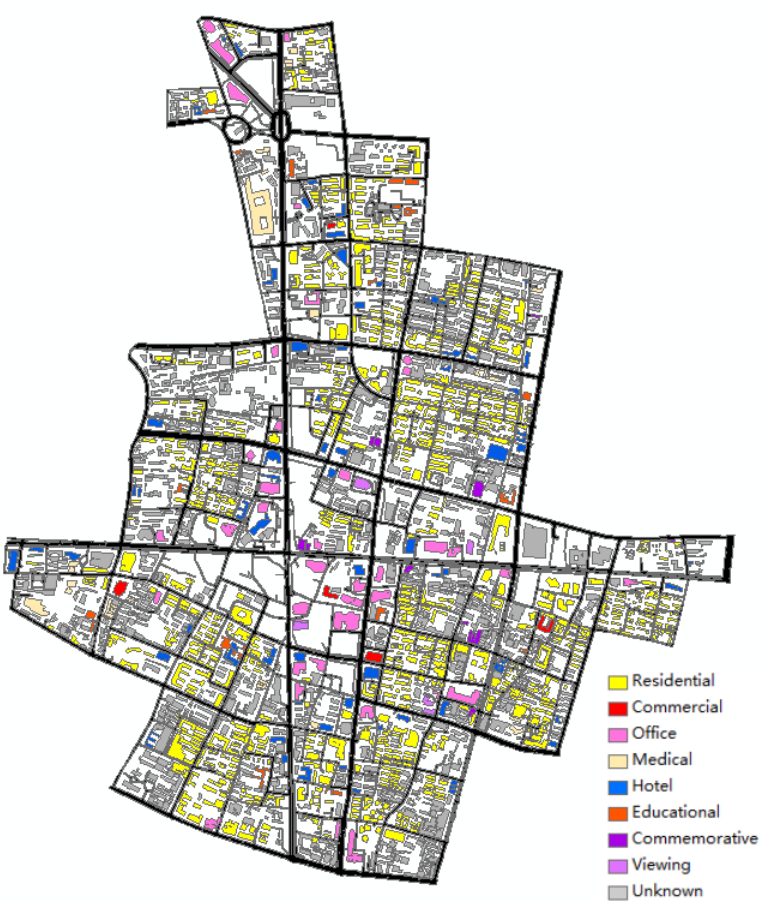

Figure 7: Building classification by BDM and POIs.

Obtaining building height or numbers of stories

The limited information of building footprints is not sufficient for the establishment of 3D city models, which generates demands for the transfer of the altitude information from POIs to building footprints so to obtain necessary information of building height or the numbers of building stories.

As mentioned above, little information of numbers of stories is available except for that of the POIs of residential and office buildings. Therefore, this paper merely discusses the acquisition of information of numbers of stories of residential buildings and office buildings. Firstly, the technical route of altitude information transfer for residential buildings is as follows (Figure 8):

(1) Add the information of POIs into polygon data;

(2) Add the information of polygon data into buildings.

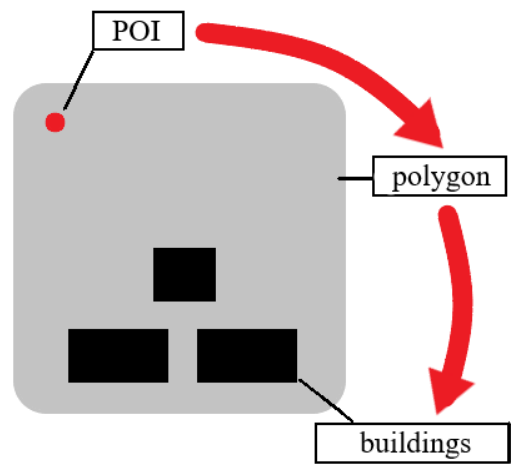

Figure 8: Technical route of information transfer.

In the first step, 71 POIs were used to add the information into 60 polygons. As is shown in Table 7, 50 polygons have only one POI, while 10 polygons have two or three POIs. In addition, 53 polygons have no POIs, which indicates the buildings on these polygons can only be identified as residential buildings, with no altitude information obtained.

Table 7: Numbers of polygons under different join counts of POIs.

\begin{tabular}{|c|c|c|c|c|}
\hline Join counts of POIs & 0 & 1 & 2 & 3 \\
\hline Numbers of polygons & 53 & 50 & 9 & 1 \\
\hline
\end{tabular}

In the second step, 60 polygons (have POIs) were used to add the altitude information into 528 buildings.

In addition, 53 POIs on building footprints were used to transfer the altitude information into 52 residential buildings. Thus, altogether 580 residential buildings contain the information of numbers of stories.

Similarly, 35 office buildings contain altitude information based on 40 POIs which are on building footprints, while the other 4 are linked with altitude information by 4 buffers.

\section{Evaluation and comparison of the data}

A surveying and mapping map (SM map, 2018, shown in Figure 9), which is from one commercial company was used to evaluate the completeness and shape accuracy of building footprints in OSM and BDM. Furthermore, field research was conducted in order to evaluate the accuracy of methods for determining building types and obtaining altitude information. 


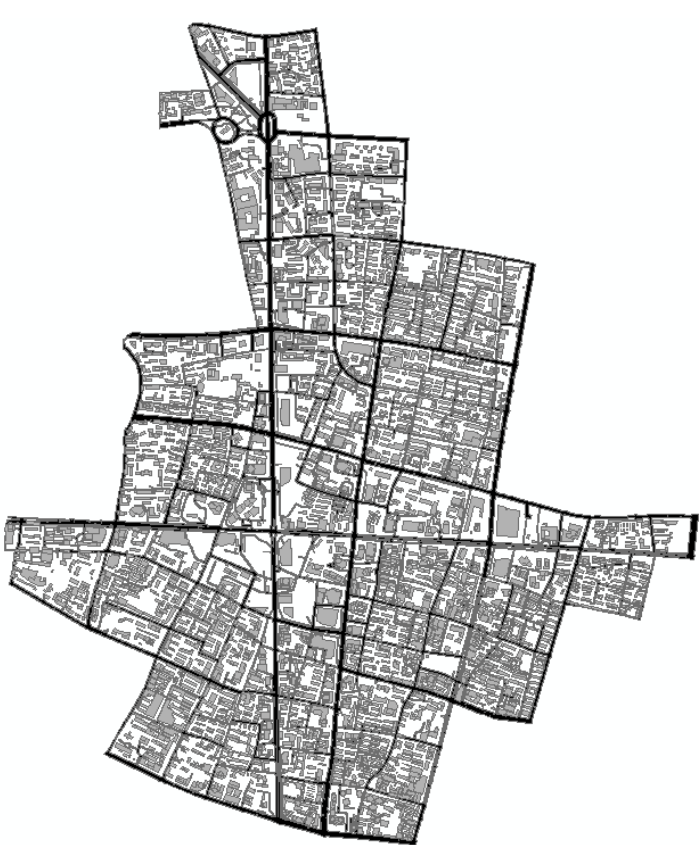

Figure 9: One SM map selected as the reference map.

\section{Building footprints}

The OSM and the reference map contain 1,133 and 2,556 building footprints, respectively. Thus, the completeness of building footprints in OSM is about $44.33 \%$, showing low integrity.

According to Fan (2014), OSM data in Germany has a high shape accuracy, as more than $75 \%$ of the building footprints have less than a $10 \%$ difference to the real building shape. However, there are few researches on shape accuracy of OSM in China. As shown in Figure 10, the shape of building footprints in OSM almost coincides with that in the reference map. Thus, the shape accuracy of OSM could be regarded relatively high with no detailed verification in this paper.
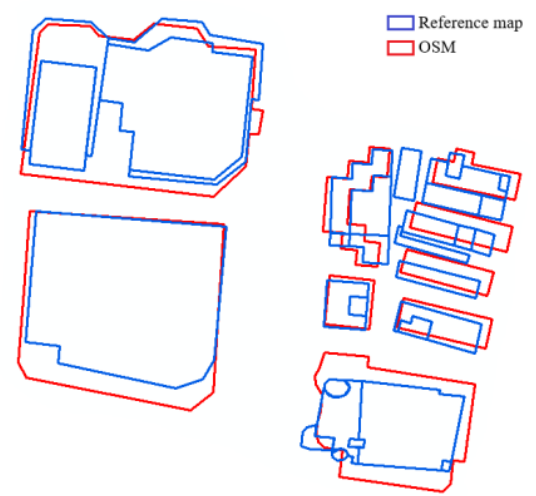

Figure 10: Comparison of building footprints between OSM and reference map.

As BDM could obtain 2,238 building footprints, the completeness of building footprints in BDM is about $87.56 \%$, nearly twice as much as that of OSM, indicating the high completeness of BDM data. Additionally, it should be noted that the footprints of some huge shopping malls are replaced by indoor scene maps in BDM which cannot be acquired by BDMapCaptureVector 1.0. This bug in the software BDMapCaptureVector 1.0 leads to the lack of the identification of 19 commercial buildings in the research area.

To evaluate the shape accuracy of building footprints, the comparison between BDM and reference map has been conducted. It is noticeable in Figure 11 that the shape of building footprints in BDM is almost same as that in the reference map, while there are no internal details in the building footprints of BDM.
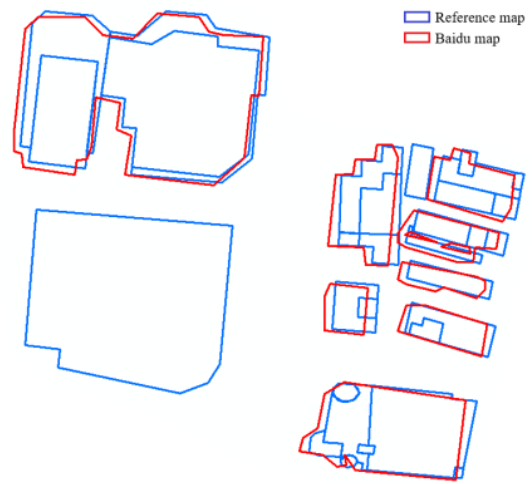

Figure 11: Comparison of building footprints between $B D M$ and reference map.

In general, BDM data has a higher completeness and shape accuracy than OSM data. In addition, BDM data contains no internal details in the building footprints, while OSM data may contain some in the footprints.

\section{Building types}

It is found that 618 buildings with specific building types, nearly $55 \%$ of total buildings, were extracted from OSM. The results of verification are shown in Table 8.

Table 8: Verification of building types in OSM.

\begin{tabular}{|c|c|c|c|}
\hline Building type & $\begin{array}{c}\text { Nos. of } \\
\text { buildings } \\
\text { (judged) }\end{array}$ & $\begin{array}{c}\text { Nos. of } \\
\text { buildings } \\
\text { (actual) }\end{array}$ & Accuracy \\
\hline Residential & 320 & 292 & $91.25 \%$ \\
\hline Office & 57 & 55 & $96.49 \%$ \\
\hline Commercial & 153 & 48 & $31.37 \%$ \\
\hline Medical & 11 & 9 & $81.82 \%$ \\
\hline Hotel & 7 & 7 & $100 \%$ \\
\hline Educational & 64 & 55 & $85.94 \%$ \\
\hline Commemorative & 3 & 3 & $100 \%$ \\
\hline Viewing & 3 & 3 & $100 \%$ \\
\hline
\end{tabular}

It is obvious that the accuracy of building classification in OSM is high, except for the determination of commercial buildings. In fact, some office buildings, hotels and residential buildings are likely to be misclassified into commercial buildings. Thus, the wrong classification of 105 commercial buildings is shown in Table 9.

Table 9: Actual building types of 105 misclassified commercial buildings.

\begin{tabular}{|c|c|c|c|}
\hline \multicolumn{2}{|c|}{ I } & \multicolumn{2}{c|}{ I } \\
\hline Office & Hotel & Residential & Others \\
\hline 46 & 4 & 50 & 5 \\
\hline
\end{tabular}

The results in Table 9 may be discussed in two aspects. In part I, as the information providers of OSM may consider hotels and office buildings as commercial buildings, the mis-classification of buildings could result from the 
imprecise classification of building types by information providers, rather than the inaccuracy of the classification method. In part $\Pi$, there is no denying that 55 buildings are misclassified owing to the inaccuracy of the classification method. Thus, OSM has a disadvantage in judging commercial buildings.

Similar to the determination of building types in OSM, the proportion of buildings which can be classified in BDM is also about $50 \%$, but a little lower than that in OSM. The accuracy of judgements of residential buildings was estimated firstly.

Table 10: Accuracy of judgements of residential buildings.

\begin{tabular}{|c|c|c|c|}
\hline Methods & $\begin{array}{c}\text { Nos. of } \\
\text { buildings } \\
\text { (judged) }\end{array}$ & $\begin{array}{c}\text { Nos. of } \\
\text { buildings } \\
\text { (actual) }\end{array}$ & Accuracy \\
\hline By polygons & 855 & 713 & $83.39 \%$ \\
\hline By POIs & 52 & 35 & $67.31 \%$ \\
\hline Total & 907 & 748 & $82.47 \%$ \\
\hline
\end{tabular}

From Table 10, the accuracy of judgements of residential buildings by using polygons is higher than that by using POIs. In addition, a total of 748 residential buildings can be correctly defined, with satisfying accuracy of over $80 \%$. From Figure 12, it is clearly to evaluate the accuracy of judgements of the other buildings. In the whole, the accuracy rate is not very high, except for those of office buildings and medical buildings.

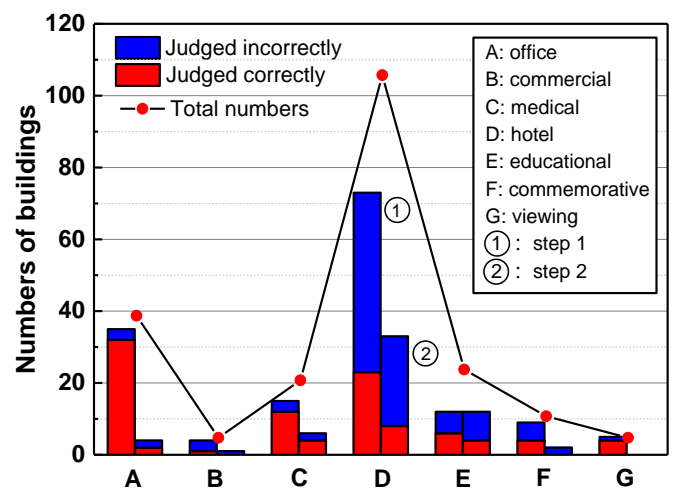

Figure 12: Accuracy of judgements of other buildings.

The reasons for the above phenomenon could be:

(1) The keywords selected for acquiring POIs are not adequate or correct enough (Overall accuracy is not high).

(2) POIs obtained from commercial housing websites are suitable for determination of building types (Accuracy of judgements of residential and office buildings is high).

(3) Nearly no mis-classification would happen in judging medical buildings due to their particularity (Accuracy of judgements of medical buildings is high).

To sum up, the determination of building types based on OSM data is better than BDM data with POIs, no matter in quantity or accuracy. However, POIs obtained from commercial housing websites offer huge potential to judge residential and office buildings in BDM.

\section{Building height or numbers of stories}

Fan (2014) notes that the altitude information of OSM data is not very rich in Germany with an integrity rate of less than $0.5 \%$. By extracting altitude information from the tag of other_tags in OSM data, the results of the integrity of altitude information are shown in Table 11. It indicates that the altitude information of OSM data is also inadequate in Nanjing.

Table 11: Integrity of altitude information in OSM.

\begin{tabular}{|c|c|c|}
\hline & $\begin{array}{c}\text { Buildings with } \\
\text { height }\end{array}$ & $\begin{array}{c}\text { Buildings with } \\
\text { numbers of stories }\end{array}$ \\
\hline Amounts & 1 & 30 \\
\hline Proportion & $0.0883 \%$ & $2.6478 \%$ \\
\hline
\end{tabular}

In BDM, as 580 residential buildings and 39 office buildings are combined with altitude information, the results show a relatively high integrity of $27.66 \%$. However, it should be noted that no altitude information has been extracted from BDM itself.

To evaluate the accuracy of the information of numbers of stories in BDM, the layer difference was used:

$$
L_{\text {dif }}=L_{\text {trans }}-L_{\text {act }}
$$

where, $L_{d i f}, L_{t r a n s}$ and $L_{a c t}$ denote layer difference, numbers of stories from POIs and actual numbers of stories, respectively.

The correctness of the numbers of stories of 308 residential and 7 office buildings is verified $\left(L_{d i f}=0\right)$, with an accuracy of $53.10 \%$ and $17.95 \%$, respectively.

In addition, as shown in Figure 13, the layer difference of the majority of the residential buildings varies from 0 to 1 , while that of most office buildings varies from -2 to 6 . Though the mean value of layer difference of residential buildings is 1.49 , higher than that of office buildings, there is much room for improvement in the quality of the altitude information transfer of residential buildings, considering the large quantity, the high accuracy and the low error of majority.

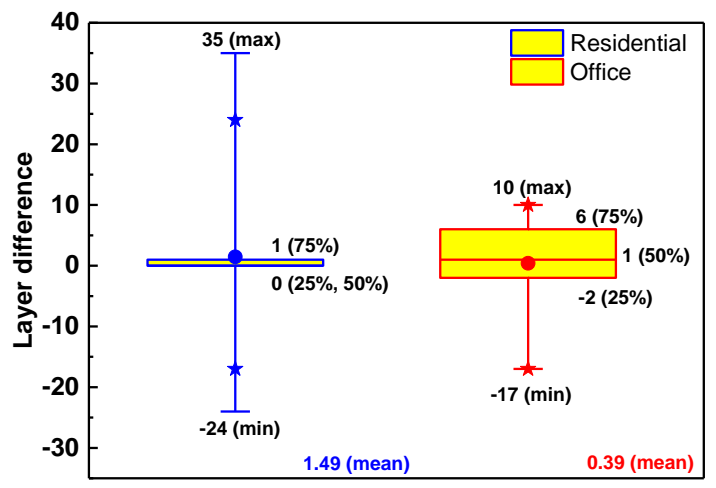

Figure 13: Box chart of layer difference.

On the whole, OSM itself has little altitude information, and no information about building height or numbers of stories has been extracted from BDM. By combining POIs with building footprints in BDM, the altitude information of residential buildings shows better quality, compared with that of office buildings.

After evaluation and comparison of OSM data and BDM data, their advantages and disadvantages are summarized in Table 12. It is found that the main difficulty of this study is the inadequate information of building height. Thus, more work needs to be done in the future. 
Table 12: Evaluation of OSM and BDM.

\begin{tabular}{|c|c|c|c|}
\hline \multicolumn{2}{|c|}{ Evaluation index } & OSM & BDM \\
\hline \multicolumn{2}{|c|}{ Data type } & .osm & .png \\
\hline \multirow{2}{*}{$\begin{array}{c}\text { Building } \\
\text { footprints }\end{array}$} & Completeness & low & high \\
\cline { 2 - 4 } $\begin{array}{c}\text { Building } \\
\text { types }\end{array}$ & Shape accuracy & high & high \\
\cline { 2 - 4 } $\begin{array}{c}\text { Altitude } \\
\text { information }\end{array}$ & Accuracy & Adequate & General \\
\cline { 2 - 4 } & $\begin{array}{c}\text { Accuracy of } \\
\text { combination }\end{array}$ & Inadequate & Noneral \\
\hline \multirow{2}{*}{$\begin{array}{c}\text { Data } \\
\text { acquired }\end{array}$} & Payment & free & $\begin{array}{c}\text { Good in } \\
\text { residential }\end{array}$ \\
\cline { 2 - 4 } & Download & Directly & By APIs \\
\hline
\end{tabular}

\section{Conclusion}

To address the problem of the both difficult and timeconsuming data collection, proper methods with high speed and using open data or semi-open data are essential for urban building energy modelers. This paper provides insights into the potential of using OSM data and BDM data in the generation of UBEM.

Building footprints, building types and building height (or numbers of stories) are three critical kinds of information for UBEM. With the information of building footprints and building height, a simple 3D city model could be established. In addition, building types are essential for archetype buildings which are widely applied to the simulation of urban building energy consumption. By using OSM, the information can be obtained on its own, together with its tags and values. However, only the information of building footprints can be acquired by BDM itself, while the acquisition of building types and building height (or numbers of stories) can be realized through the combination of BDM and POIs.

The evaluation on the information mined from OSM and BDM has been conducted. Firstly, the results in the assessments of building footprints show that the completeness and shape accuracy is higher in BDM than that in OSM. Then, the tags or values, and the types of land use were used for the determination of building types in OSM, of which the results show that $55 \%$ of the total buildings can be quickly classified, with higher accuracy than that by BDM with POIs. Finally, despite of very little altitude information in OSM or BDM, the transfer of the information from POIs to buildings could be done in order to add altitude information into building footprints in BDM. The accuracy of altitude information transfer in residential buildings is over $53 \%$, and the quality of the transfer is better than that in office buildings, no matter in quantity, accuracy or error of majority.

\section{Acknowledgement}

This paper is financially supported by the National Natural Science Foundation of China (grant number: 51678124).

\section{References}

Alhamwi, A., Medjroubi, W., Vogt, T., Agert, C. (2017). OpenStreetMap data in modelling the urban energy infrastructure: a first assessment and analysis.
Proceedings from the $9^{\text {th }}$ International Conference on Applied Energy. Cardiff (UK), 21-24 August 2017.

Cerezo Davila, C., Jones, N., Al-Mumin, A., Hajiah, A., Reinhart, C.F. (2017). Implementation of a calibrated Urban Building Energy Model (UBEM) for the evaluation of energy efficiency scenarios in a Kuwaiti residential neighborhood. Proceedings from the $15^{\text {th }}$ IBPSA Conference. San Francisco (USA), 7-9 August 2017.

Chen, Y., Hong, T., Piette, M.A. (2017). City-Scale Building Retrofit Analysis: A Case Study using CityBES. Proceedings from the $15^{\text {th }}$ IBPSA Conference. San Francisco (USA), 7-9 August 2017.

Damassa, T., Ge, M., Fransen, T. (2014). The U.S. Greenhouse Gas Reduction Targets.

Fan, H., Zipf, A., Fu, Q., Neis, P. (2014). Quality assessment for building footprints data on OpenStreetMap. Journal of Geographical Information Science 28(4), 700-719.

Li, W., Zhou, Y., Cetin, K.S., Yu, S., Wang, Y., Liang, B. (2018). Developing a landscape of urban building energy use with improved spatiotemporal representations in a cool-humid climate. Journal of Building and Environment 136, 107-117.

Lin, F.Y., Lin, T.P., Hwang, R.L. (2017). Using geospatial information and building energy simulation to construct urban residential energy use map with high resolution for Taiwan cities. Journal of Energy and Buildings 157, 166-175.

Mata, E., Kalagasidis, A.S., Johnsson, F. (2014). Building-stock aggregation through archetype buildings: France, Germany, Spain and the UK. Journal of Building and Environment 81, 270-282.

Monteiro, C.S., Costa, C., Pina, A., Santos, M.Y., Ferrao, P. (2018). An urban building database (UBD) supporting a smart city information system. Journal of Energy and Buiuldings 158, 244-260.

Nouvel, R., Zirak, M., Coors, V., Eicker, U. (2017). The influence of data quality on urban heating demand modeling using 3D city models. Journal of Computers, Environment and Urban Systems 64, 68-80.

Reinhart, C.F., Cerezo Davila, C. (2016). Urban building energy modeling-A review of a nascent field. Journal of Building and Environment 97, 196-202.

Remmen, P., Lauster, M., Mans, M., Fuchs, M., Osterhage, T., Muller, D. (2018). TEASER: an open tool for urban energy modelling of building stocks. Journal of Building Performance Simulation 11(1), 84-98.

Sokol, J., Cerezo Davila, C., Reinhart, C.F. (2017). Validation of a Bayesian-based method for defining residential archetypes in urban building energy models. Journal of Energy and Buiuldings 134, 11-24. 